\title{
Procreation without recreation
}

\author{
Stephen B Hanauer
}

Of late, science and government have interacted over two seemingly disparate topics: the requirement for teaching of 'intelligent design' as an alternative hypothesis to evolution in US schools and the legality of stem cell research. There is, however, a great deal of similarity between the two issues. It is easy to distill the two issues into debates on evolution versus devolution, and how modern governments impact on science and scientific discovery.

On December 20, 2005, district judge John E Jones III, an appointee of US President George W Bush, ruled that the Dover Area School District, Pennsylvania, USA, could not insist that their biology teachers read a statement about intelligent design in their classes. His ruling stated that intelligent design is another name for creationism. The message of an editorial by Robert S Schwartz, published in October 2005 (N Engl J Med 353: 1437-1439), is that intelligent design is a pseudoscience propounded by faith healers and he urged scientists against entering debate as a legitimizing maneuver. By (modest) contrast, a more recent editorial (Lancet 367: 2) described such debates as “...hard going, but it is exactly this kind of interaction that is sorely needed ... [to engage] the public with the values and victories of science and medicine...". The debate is heated because a substantial proportion of the US population is open to the concept of creationism, including the current President. Nevertheless, science prevailed in the justice system-at least for the time being.

Almost concurrently is the debate regarding stem cell research and the scandal involving

\section{While attempts at genetic devolution will probably succeed... we can still derive pleasure from our current evolutionary procedures...}

SB Hanauer is Editorin-Chief of Nature Clinical Practice Gastroenterology \& Hepatology.

\section{Competing interests}

The author declared he has no competing interests.

www.nature.com/clinicalpractice doi:10.1038/ncpgasthep0441
Woo-Suk Hwang of Seoul National University, South Korea. In the reputable scientific journal Science, Hwang fraudulently published a paper describing the generation of a number of pluripotent human embryonic stem cell lines, achieved by nuclear transfer of an adult somatic cell into an unfertilized oocyte, which progressed to the blastocyst stage and bore an identical genetic profile to that of the donor. In their editorial, Evan Y Snyder and Jeanne F Loring (N Engl J Med 354: 321-324) provide a reassuring perspective that science and the scientific method, along with appropriate peer review (and not government intervention), was able to identify the fraud. They emphasize that prevaricators might transiently exploit the system, but that "...truth in science is minted only after many investigators have replicated a finding." They also review the potential complicity of the South Korean Government by encouraging Hwang to publish prematurely (note the rise in South Korean national pride and its subsequent disgrace). Their transient monopoly on this technical advance contrasts with the delay in requisite studies undertaken to validate Hwang's 'discoveries' caused by US Federal Government restrictions on stem cell research.

Apparently, Hwang's designs were not as intelligent as first described, but scientific methods prevailed. While attempts at genetic devolution will probably succeed in future experiments (hopefully for the betterment of mankind), we can still derive pleasure from our current evolutionary procedures, as long as 'big brother' is not overly intrusive regarding our personal, and scientific, endeavors. 